\title{
Endoscopic clip closure of a duodenocolic fistula secondary to a migrated biliary stent
}

A 72-year-old man presented with acute cholangitis. He underwent endoscopic retrograde cholangiography (ERCP), which revealed a type IIIb Klatskin tumor. An 8.5-Fr, $12-\mathrm{cm}$ plastic biliary stent was placed. Cholangiocarcinoma was confirmed cytologically and this was deemed unresectable.

One month later, the patient presented with abdominal pain and cholestasis without peritoneal signs, fever, or leukocytosis. A computed tomography (CT) scan revealed that the stent had migrated and caused a duodenocolic fistula without any associated collection ( $\mathbf{F i g}$. 1). Broadspectrum antibiotics were commenced and a repeat ERCP confirmed that the 8.5-Fr stent had perforated the duodenal wall ( $\bullet$ Fig. 2a). The stent was retrieved with a foreign-body forceps. A punctate perforation was evident following removal of the stent ( Fig. $\mathbf{2 b}$ ) and this was closed with a through-the-scope clip ( $\bullet$ Fig. 2c). Cholangiography demonstrated left intrahepatic biliary dilatation and an uncovered biliary metal stent was implanted ( Video 1 ). The patient was discharged 3 days after the procedure.

There are only three reported cases of duodenocolic fistula due to biliary stent migration [1-3]. The most common mechanism of perforation after biliary stent migration is direct contact [4]. Gastrointestinal perforations can be treated endoscopically with clip placement in acute or deferred presentation in patients where there are no signs of peritonitis [4, 5]. The over-the-scope clip has also been used to close duodenocolic fistulas secondary to a migrated biliary stent [6-8], though this is probably not required in chronic cases with small fistulas or perforations. Clinicians should be aware of the endoscopic management options in such cases, thereby avoiding the need for surgical intervention, even in the setting of colonic involvement. This is the first report of a patient who underwent endoscopic removal of the migrated biliary stent and closure of the fistula with a clip.

Endoscopy_UCTN_Code_CPL_1AK_2AD

Competing interests: None

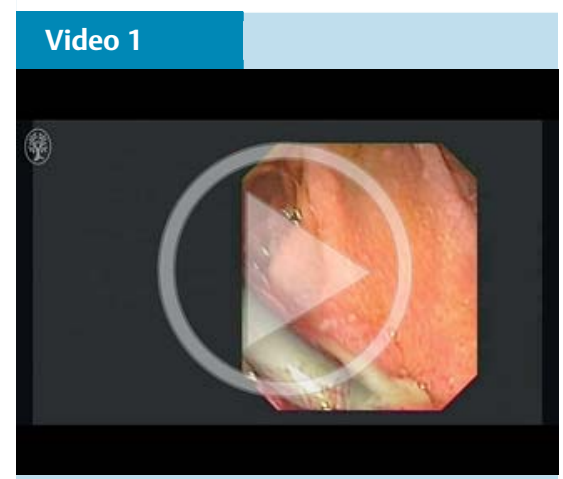

Removal of a migrated plastic biliary stent that had caused a duodenocolic fistula leaves behind a punctate perforation in the duodenal wall that is closed by a through-the-scope clip, with a metal stent being placed through the papilla to relieve the biliary dilatation.
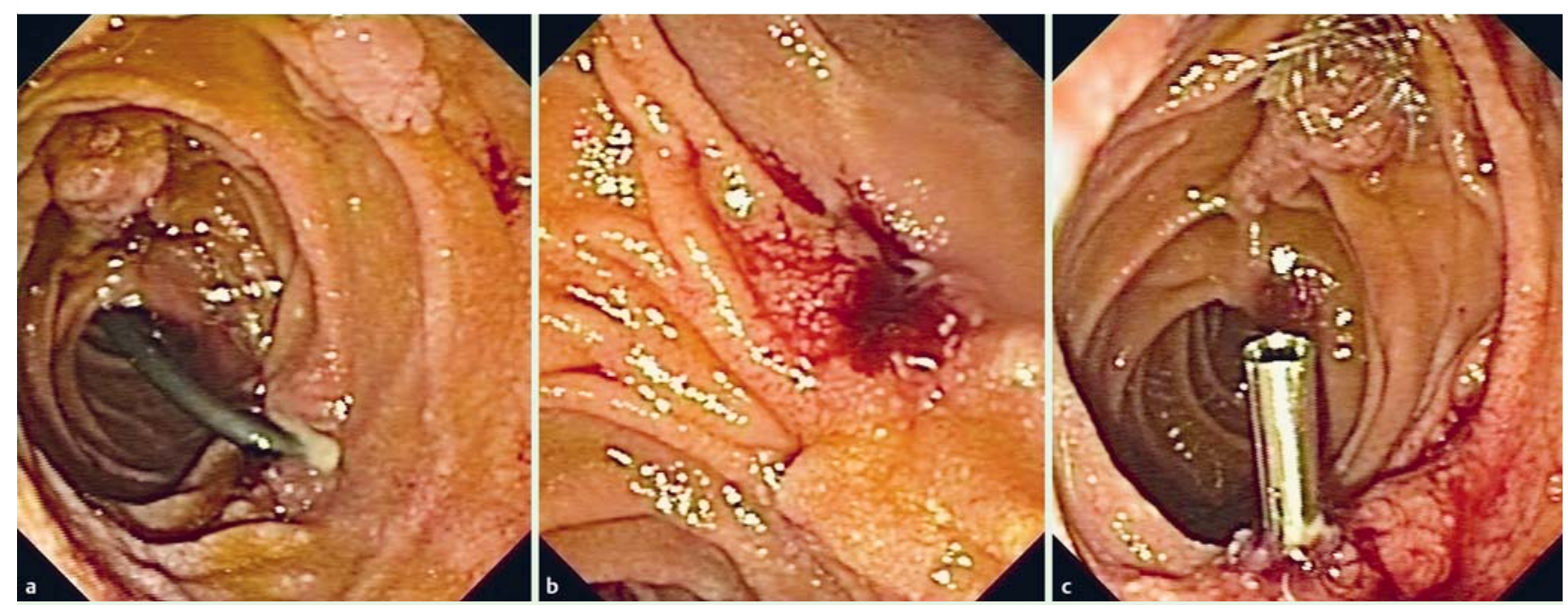

Fig. 2 Endoscopic views showing: a a plastic stent perforating the wall of the duodenum; $\mathbf{b}$ a punctate perforation following removal of the migrated stent; c a through-the-scope clip that was placed to close the perforation and the end of a biliary metal stent that was placed through the papilla. 


\section{Ramon Sanchez-Ocaña, Carlos \\ Chavarria-Herbozo, Andrés Figueroa \\ Marrero, Maria-Teresa Herranz \\ Bachiller, Irene Peñas-Herrero, \\ Carlos de la Serna-Higuera, \\ Manuel Perez-Miranda}

Division of Gastroenterology, Hospital

Universitario Rio Hortega, Valladolid, Spain

\section{References}

1 Diller R, Senninger N, Kautz G et al. Stent migration necessitating surgical intervention. Surg Endosc 2003; 17: 1803-1807

2 Ang BK, Wee SB, Kaushik SP et al. Duodenalcolic fistula resulting from migration of a biliary stent: a case report. Gastrointest Endosc 1998; 48: 80-83

3 Javia SB, Patel R, Singhal S. Endoscopic closure with an over-the-scope clip of a duodenocolonic fistula caused by a migrated biliary stent. Gastrointest Endosc 2016; 83 : 845-847
4 Alcaide N, Lorenzo-Pelayo S, Herranz-Bachiller MT et al. Sigmoid perforation caused by a migrated biliary stent and closed with clips. Endoscopy 2012; 44: (Suppl. 02): E274

5 Roses $L L$, Ramirez AG, Seco AL et al. Clip closure of a duodenal perforation secondary to a biliary stent. Gastrointest Endosc 2000; 51: 487-489

6 Mennigen $R$, Senninger N, Lauokoetter MG. Novel treatment options for perforations of the upper gastrointestinal tract: endoscopic vacuum therapy and over-the-scope clips. World J Gastroenterol 2014; 20: 7767- 7776

7 Bertolini R, Meyenberger C, Sulz MC. First report of colonoscopic closure of a gastrocolocutaneous PEG migration with over-thescope-clip-system. World J Gastroenterol 2014; 20: 11439-11442

8 Wedi E, Gonzalez S, Menke D et al. One hundred and one over-the-scope-clip applications for severe gastrointestinal bleedings, leaks and fistulas. World J Gastroenterol 2016; $22: 1844-1853$
Bibliography

Dol http://dx.doi.org/

10.1055/s-0042-109055

Endoscopy 2016; 48: E230-E231

(c) Georg Thieme Verlag KG

Stuttgart · New York

ISSN 0013-726X

Corresponding author

Ramon Sanchez-Ocaña, MD

Division of Gastroenterology

Hospital Universitario Rio Hortega

Calle Dulzaina 2

47014, Valladolid

Spain

ramonsocana@gmail.com 